\title{
Symmetric Bilateral Aberrant Obturator Artery. A Case Report
}

\author{
Arteria Obturatriz Aberrante Simétrica Bilateral. Reporte de un Caso
}

\begin{abstract}
Aladino Cerda ****
CERDA, A. Symmetric bilateral aberrant obturator artery. A case report. Int. J. Morphol., 34(3):1083-1086, 2016.

SUMMARY: Aberrant obturator artery (AOA) is an anatomical variation in the origin and course of the obturator artery, which is clinically important because of their vulnerability during surgical procedures performed in the pelvis. This article describes the case of a symmetrical AOA found in both hemipelvises of a male cadaver. Morphological and morphometric characteristics are presented, while their clinical significance is discussed.
\end{abstract}

KEY WORDS: Obturator artery; Aberrant obturator artery; Corona mortis; Pelvis.

\section{INTRODUCTION}

Obturator artery is one of the parietal extrapelvic branches of the internal iliac artery, which runs along the lateral wall of the pelvis and passes through the obturator foramen to reach and irrigate the medial region thigh muscles and the hip joint. It's origin is variable, usually emerging near the umbilical artery (Moore, 2010). One variation of the obturator artery is aberrant obturator artery (AOA), which is originated from the external iliac artery or the inferior epigastric artery, arching above and behind the superior pubic ramus, descends towards the obturator foramen, completely replacing the irrigation provided by the obturator artery (Baena et al., 2015). The name of this vessel is precisely due to its origin and anomalous course (Darmanis et al., 2007). In the retropubic region it is also possible to find the corona mortis artery, which corresponds to a branch that usually originates from the external iliac artery or inferior epigastric artery, coexists with the obturator artery and anastomoses with it, forming an arc around the superior pubic ramus (Berberoglu, et al., 2001; Smith et al., 2009;. Rusu et al., 2010; Sakthivelavan et al., 2010). Such vascular variant acquires its name (crown of death) product of vital risk to which the person is exposed after accidental injury, which leads to a large bleeding, difficult to manage (Smith et al.; Stavropoulou-Deli \& Anagnostopoulou, 2013; Baena et al.).

According to Rusu et al., there is no consensus regarding the terminology for these variant vessels emerging from the system of the external iliac artery, since authors as Mahato (2009) refer to the AOA as corona mortis artery in the absence of the obturator artery. The truth is that these two forms of variation pose a risk in surgical procedures involving the inferior part of the anterior abdominal wall, because vessels run above and behind the superior pubic ramus (Baena et al.).

In this article the case of a symmetrical AOA is described, found in both hemipelvises of a male cadaver from the morphology laboratory of the Universidad de Talca (Chile). The bilateral symmetry of these vessels is very rare and its incidence is unknown in our country.

The purpose of this report was to describe the morphological and morphometric characteristics of this variation, its relations and clinical and surgical importance.

\section{CASE REPORT}

During a routine dissection of the pelvis in a male cadaver that belongs to the morphology laboratory of the Universidad de Talca, the presence of a bilateral vascular variation was found. The obturator region and the back face of the pubis were carefully dissected, and identified the elements passing through the obturator foramen.

\footnotetext{
* Unidad de Morfología, Departamento de Ciencias Básicas Biomédicas, Facultad de Ciencias de la Salud, Universidad de Talca, Talca, Chile.

** Programa de Magíster en Ciencias, mención Morfología, Facultad de Ciencias de la Salud, Universidad de La Frontera, Temuco, Chile.
} 
The obturator artery presented an aberrant origin and course in both hemipelvises, originating from the inferior

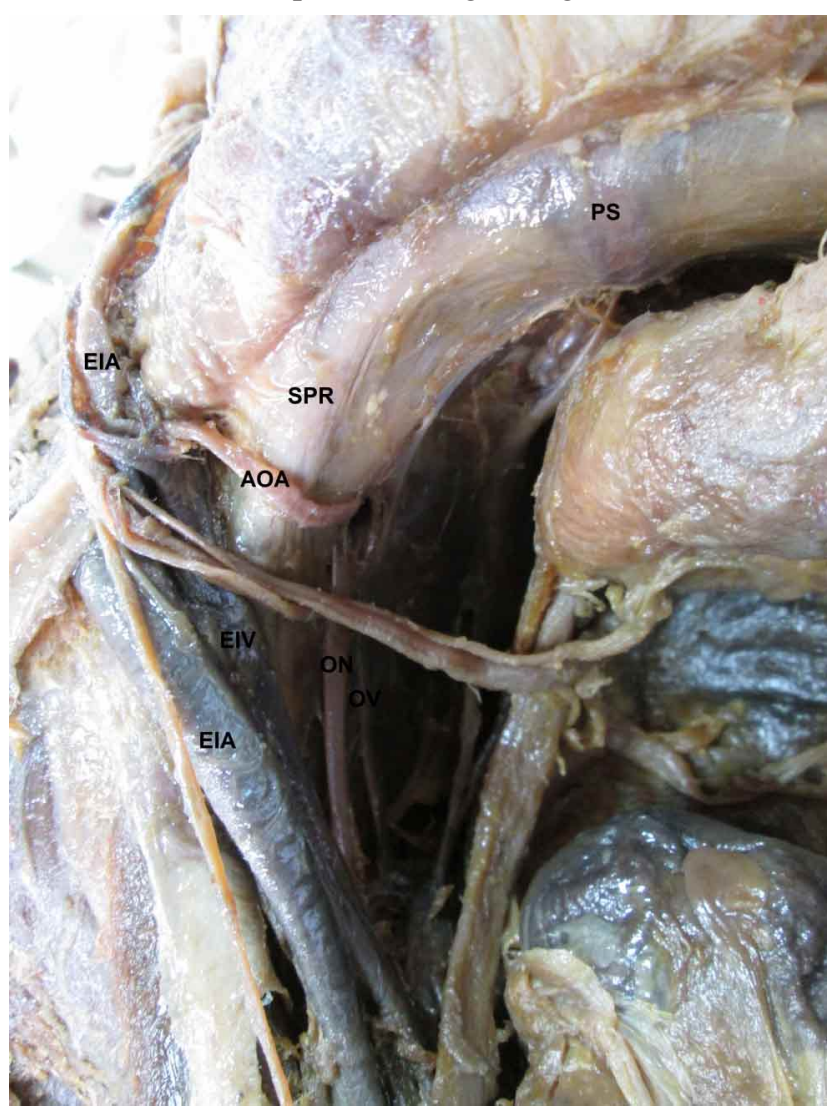

Fig. 1. Origin of the aberrant obturator artery from the inferior epigastric artery in the left hemipelvis. PS = pubic symphysis; EIA $=$ epigastric inferior artery; $\mathrm{SPR}=$ superior pubic ramus; $\mathrm{AOA}=$ aberrant obturator artery; EIA = external iliac artery; EIV = external iliac vein; $\mathrm{ON}=$ obturator nerve; $\mathrm{OV}=$ obturator vein.

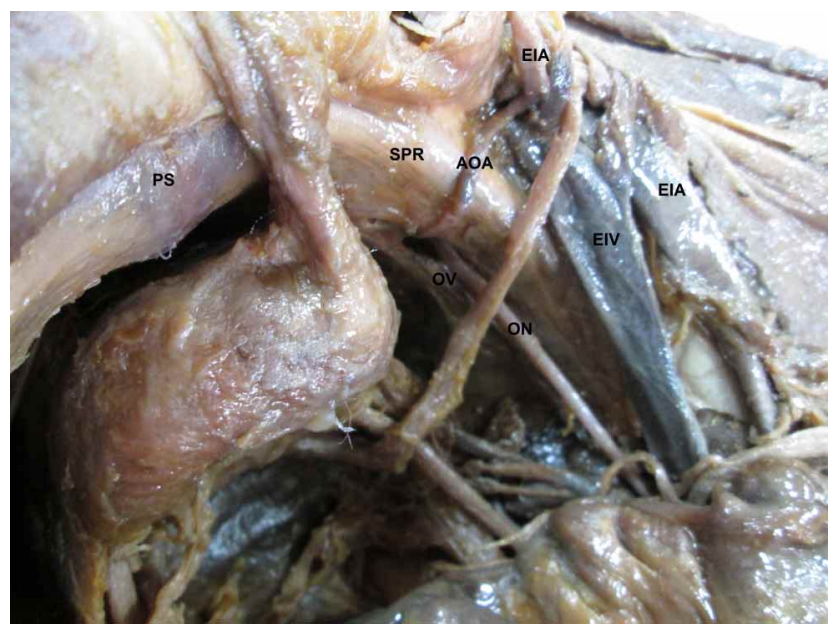

Fig. 2. Origin of the aberrant obturator artery from the inferior epigastric artery in the right hemipelvis. $\mathrm{PS}=$ pubic symphysis; $\mathrm{EIA}=$ epigastric inferior artery; $\mathrm{SPR}=$ superior pubic ramus; $\mathrm{AOA}$ = aberrant obturator artery; EIA = external iliac artery; EIV = external iliac vein; $\mathrm{ON}=$ obturator nerve; $\mathrm{OV}=$ obturator vein. epigastric artery. In the left hemipelvis (Fig. 1), its length was $36.41 \mathrm{~mm}$ and the diameter at the origin was $2.77 \mathrm{~mm}$, whereas in the right hemipelvis (Fig. 2), its length was $36.93 \mathrm{~mm}$ and the diameter at the origin was $2.8 \mathrm{~mm}$. Both vessels formed an arc around the superior pubic ramus, and going back to it reaching the obturator foramen. Right AOA was found to 49.23 $\mathrm{mm}$ from pubic symphysis and $6.29 \mathrm{~mm}$ from the arc of the lacunar ligament; left AOA, to $47.24 \mathrm{~mm}$ from pubic symphysis and $5.11 \mathrm{~mm}$ from the arc of the lacunar ligament.

\section{DISCUSSION}

According to Pick et al. (1942), the AOA has been the most studied retropubic vessel, because of its responsibility towards injury during the repair of femoral hernias. Several studies report its incidence from the inferior epigastric artery by $8 \%, 14.81 \%, 22 \%$ and $27.34 \%$, respectively (Mahato; Sarikcioglu et al., 2003; Lau \& Lee, 2003; Pick et al.). The great variability of these incidents may be due to regional differences in the development of the vascular system, difficulties in dissecting the collapsed vessels on the cadavers and the limitations caused by the size of these vessels (Okcu et al., 2004). In surgery, the presence of an abnormal arc around the superior pubic ramus is lower than in anatomical dissections (Darmanis et al.), possibly due to vascular spasm product traumatic laceration, which makes it difficult to identify (Okcu et al.).

Lau \& Lee justify the presence of the AOA, stating that the occlusion of the obturator artery secondary to any cause, such as atherosclerosis or deep vein thrombosis, can lead to the development of collateral circulation and the subsequent formation of aberrant obturator vessels. However, as stated by Darmanis et al., last theory seems to ignore the probably obvious finding that the occluded vessels and their branches would still be present, although as fibrous bands, which are not evident in this case. Pai et al. (2009) tried to give it an embryological explanation for the presence of the AOA, indicating that the arterial patterns of limbs are based on an unusual selection of trajectory from a primary capillary plexus, in which the most suitable passage expands while others retract and disappear, thus establishing the final pattern. Before the obturator artery appears as a separate vessel from pelvic vascular system, blood flow dedicated to this area makes an unusual choice from the source trajectory and instead originate from the internal iliac artery as usually occurs, it arises from the inferior epigastric artery.

The length of aberrant obturator artery in this report is lower than the average indicated by Baena et al. ( $49 \pm$ $8.73 \mathrm{~mm}$ ), while its diameter was smaller than the case 
described by Darmanis et al. $(4.7 \mathrm{~mm})$, but similar to the reported by Baena et al. $(3 \mathrm{~mm})$. The distance between the pubic symphysis and aberrant obturator vessels in this case is comparable to the findings of Sarikcioglu et al., $(39.79 \pm 11.42 \mathrm{~mm})$ and Berberoglu, et al. (Between 33.2 and $52.7 \mathrm{~mm}$ ), while the distance between the arc of the lacunar ligament and aberrant vessels was less than described by Sarikcioglu et al. $(12.18 \pm 3.55 \mathrm{~mm})$. These differences may be due to demographic and ethnic characteristics of the studied cadavers.

The distance between the pubic symphysis and the AOA has significance for surgeons during an anterior boarding to the acetabulum, as may be encountered with that vessel between 40 and $96 \mathrm{~mm}$ lateral to the pubic symphysis, although this potential danger should not compromise the surgical decision to operate through the ilioinguinal approach for fear of excessive bleeding, since it does not appear to be a significant clinical risk (Darmanis et al.).

The distance between the AOA and the arc of the lacunar ligament is relevant because it indicates the risk of injury to these vessels during surgery of the femoral hernia (Sakthivelavan et al.). When the lacunar ligament is opened, this branch vessel that passes behind it, above Cooper's ligament, could be damaged product of the staples or tacks placed on Cooper's ligament, leading to potentially fatal bleeding (Sabuncuoglu et al., 2015). The unexpected presence of the AOA can become a problem for the orthopaedic surgeon, urologist, gynecologist and general surgeon, any of which can perform surgical procedures in this area (Skandalakis et al., 2000). However, in clinical practice the incidence of excessive bleeding of these variant vessels is extremely low (Darmanis et al.). Smith et al., describe the case of a patient with a lesion in an aberrant obturator artery originating from the inferior epigastric artery, the result of a fracture of the superior pubic ramus and isquiopubic ramus.

In all clinical studies and reports it is evident that these retropubic anastomotic vessels are paramount for surgeons who deal with pelvic and acetabular trauma (Darmanis et al.). Such vessels cross the superior pubic ramus in a relatively vertical direction and, therefore, are susceptible to injury during dissection of the preperitoneal space. The entire section of the AOA, which can occur during pelvic surgery, could lead to a dangerous bleeding and difficult hemostasis, especially when the divided vessel retracts through the obturator foramen (Lau \& Lee).

According to Pai et al., the advantage of the presence of the AOA is that in case of internal iliac artery and its collateral ligation in patients undergoing pelvic surgery and in cases of internal iliac artery obstruction due to any cause, the AOA and its branches would be preserved, especially the branch to the femoral head.

The fact that the AOA crosses the posterior face of the superior pubic ramus, exposes it to pelvic trauma and multiple surgical procedures performed at this level. A good knowledge of the retropubic vascular anatomy is essential before surgical approach to this region.

CERDA, A. Arteria obturatriz aberrante simétrica bilateral. Reporte de un caso. Int. J. Morphol., 34(3):1083-1086, 2016.

SUMMARY: La arteria obturatriz aberrante (AOA) es una variación anatómica del origen y trayecto de la arteria obturatriz que tiene importancia clínica debido a su vulnerabilidad durante los procedimientos quirúrgicos realizados en la pelvis. En este artículo se describe el caso de una AOA simétrica encontrada en ambas hemipelvis de un cadáver masculino. Se presentan sus características morfológicas y morfométricas, y se discute su importancia clínica.

PALABRAS CLAVE: Arteria obturatriz; Arteria obturatriz aberrante; Corona mortis; Pelvis.

\section{REFERENCES}

Baena, G.; Rojas, S. \& Peña, E. Corona mortis: Anatomical and clinical relevance and occurrence in a sample of the Colombian population. Int. J. Morphol., 33(1):130-6, 2015.

Berberoglu, M.; Uz, A.; Ozmen, M. M.; Bozkurt, M. C.; Erkuran, C.; Taner, S.; Tekin, A. \& Tekdemir, I. Corona mortis: an anatomic study in seven cadavers and an endoscopic study in 28 patients. Surg. Endosc., 15(1):72-5, 2001.

Darmanis, S.; Lewis, A.; Mansoor, A. \& Bircher, M. Corona mortis: an anatomical study with clinical implications in approaches to the pelvis and acetabulum. Clin. Anat., 20(4):433-9, 2007.

Lau, H. \& Lee, F. A prospective endoscopic study of retropubic vascular anatomy in 121 patients undergoing endoscopic extraperitoneal inguinal hernioplasty. Surg. Endosc., 17(9):1376-9, 2003.

Mahato, N. K. Retro-pubic vascular anomalies: A study of abnormal obturator vessels. Eur. J. Anat., 13(3):121-6, 2009.

Moore, K. L.; Dalley, A. F. \& Agur, A. M. R. Anatomía con Orientación Clínica. $6^{\mathrm{a}}$ ed. Barcelona, Wolters Kluwer, Lippincott Williams \& Wilkins, 2010. 
Okcu, G.; Erkan, S.; Yercan, H. S. \& Ozic, U. The incidence and location of corona mortis: a study on 75 cadavers. Acta Orthop. Scand., 75(1):53-5, 2004.

Pai, M. M; Krishnamurthy, A.; Prabhu, L. V.; Pai, M. V.; Kumar, S. A. \& Hadimani, G. A. Variability in the origin of the obturator artery. Clinics (Sao Paulo), 64(9):897-901, 2009.

Pick, J. W.; Anson, B. J. \& Ashley, F. L. The origin of the obturator artery. A study of 640 body-halves. Am. J. Anat., 70(2):31743, 1942.

Rusu, M. C.; Cergan, R.; Marius, A. G.; Folescu, R. \& Pop, E. Anatomical considerations on the corona mortis. Surg. Radiol. Anat., 32(1):17-24, 2010.

Sabuncuoglu, M. Z.; Dandin, O. \& Kiliç, C. A new anatomical approach to laparoscopic hernia repair: Triangle of dissection. Clin. Anat., 28(8):965-6, 2015.

Sakthivelavan, S.; Sendiladibban, S. D.; Aristotle, S. \& Sivanandan, A. V. Corona mortis - a case report with surgical implications. I. J. A. V. Int. J. Anat. Var., 3:103-5, 2010.

Sarikcioglu, L.; Sindel, M.; Akyildiz, F. \& Gur, S. Anastomotic vessels in the retropubic region: corona mortis. Folia Morphol. (Warsz), 62(3):179-82, 2003.

Skandalakis, L. J.; Androulakis, J.; Colborn, G. L. \& Skandalakis, J. E. Obturator hernia. Embryology, anatomy, and surgical applications. Surg. Clin. North Am., 80(1):71-84, 2000.

Smith, J. C.; Gregorius, J. C.; Breazeale, B. H. \& Watkins, G. E. The corona mortis, a frequent vascular variant susceptible to blunt pelvic trauma: identification at routine multidetector CT. J. Vasc. Interv. Radiol., 20(4):455-60, 2009.

Stavropoulou-Deli, A. \& Anagnostopoulou, S. Corona mortis: anatomical data and clinical considerations. Aust. N. Z. J. Obstet. Gynaecol., 53(3):283-6, 2013.
Correspondence to:

Aladino Cerda Alarcón

Universidad de Talca

Departamento de Ciencias Básicas Biomédicas

Avenida Lircay s/n Oficina $\mathrm{N}^{\circ} 1$

Talca

CHILE

Email:alcerda@utalca.cl

Received: 08-03-2016

Accepted: 05-07-2016 